\title{
A PERCEPÇÃO DE EPÊNTESE VOCÁLICA E DE ACENTO DE PALAVRA NO INGLÊS COMO LÍNGUA FRANCA
}

\author{
The Perception of Vowel Epenthesis and Word Stress in the English as a Lingua Franca \\ Context
}

\author{
Maria Lúcia de Castro GOMES, UTFPR ${ }^{1}$ \\ Andressa BRAWERMAN-ALBINI, UTFPR ${ }^{2}$
}

\begin{abstract}
RESUMO: Este artigo tem por objetivo apresentar dois estudos que investigaram a inteligibilidade da produção de palavras que terminam com o morfema $-e d$ e da produção de palavras pré-proparoxítonas sufixadas por falantes brasileiros. Três grupos de ouvintes, falantes nativos de inglês, falantes brasileiros de inglês e falantes de inglês não-nativos e não brasileiros transcreveram sentenças produzidas por brasileiros com diferentes níveis de proficiência em inglês. A inteligibilidade do inglês brasileiro é discutida a partir da perspectiva do Inglês como Lingua Franca (JENKINS, 2000) e de acordo com as proposições da Linguística Probabilística (BOD; HAY; JANEDY, 2003). A grande relevância deste estudo é a contribuição para a pesquisa em segunda língua, especialmente em relação ao núcleo de língua franca e a percepção do inglês de falantes brasileiros.
\end{abstract}

PALAVRAS-CHAVE: inglês; língua franca; percepção; epêntese; acento.

ABSTRACT: This article aims at presenting two studies that investigated the intelligibility of Brazilian speakers' production of words ending with the -ed morpheme and production of words stressed on the fourth to last syllable of suffixed English words. Three groups of listeners, English native speakers, Brazilian speakers, and non-native speakers other than Brazilians transcribed the sentences produced by Brazilians with different levels of English proficiency. Under the assumption of English as a Lingua Franca (Jenkins, 2000) and the propositions of Probabilistic Linguistics (Bod, Hay \& Janedy, 2003), the intelligibility of Brazilian English is discussed. The great relevance of this study is the contribution to second language research, especially regarding the lingua franca core and the perception of Brazilian speakers' English.

KEY WORDS: English; lingua franca; perception; epenthesis; stress.

\footnotetext{
${ }^{1}$ Doutora em Letras pela UFPR (2009), professor adjunto na UTFPR.http://lattes.cnpq.br/3965335762513000

${ }^{2}$ Doutora em Letras pela UFPR (2012), professor adjunto I na UTFPR. http://lattes.cnpq.br/0904067563497910
} 


\section{INTRODUÇÃO}

O ponto de partida para este artigo é o fato de que o Inglês é hoje um instrumento de comunicação mundial entre pessoas de diferentes nacionalidades, e que cada vez mais conversas em inglês são realizadas sem a presença de um falante nativo. Abordando fatos sociolinguísticos de variação, Jenkins (2000) propõe um núcleo de língua franca (Lingua Franca Core - LFC) - um conjunto de prioridades na área de pronúncia para o ensino de inglês. Ao estabelecer essas prioridades, Jenkins afirma que na produção de encontros consonantais, a epêntese é preferível ao apagamento da consoante. Ela também menciona que a colocação inadequada do acento na palavra raramente causa problemas de inteligibilidade para falantes não-nativos. Embora essas duas características não estejam incluídas no LFC de Jenkins, elas geralmente são problemáticas na produção de inglês por brasileiros. De acordo com vários estudos, um aspecto relevante do sotaque de um falante brasileiro de inglês é a produção de uma vogal epentética em palavras com o morfema -ed (ALVES, 2004; DELATORRE, 2006; GOMES, 2009). Quanto à colocação de acento, Brawerman (2006) mostra que os brasileiros têm dificuldades com o acento de palavras pré-proparoxítonas em inglês. Com base nesses trabalhos, este artigo vai apresentar os resultados de um estudo sobre a percepção dos verbos no passado regular e de palavras com o padrão pré-proparoxítono produzido por falantes brasileiros. Os ouvintes foram divididos em três grupos de falantes de inglês: um com falantes nativos, um com falantes não-nativos exceto brasileiros, e um com falantes brasileiros. O objetivo da pesquisa foi testar o LFC de Jenkins em relação aos fenômenos da epêntese e do acento de palavra, e também fazer uma relação dos resultados obtidos a efeitos de frequência, tendo como base a linguística probabilística. Este estudo é relevante por sua contribuição para a pesquisa em segunda língua, especialmente considerando o LFC e a percepção do inglês falado por brasileiros.

\section{AS BASES TEÓRICAS}

Durante décadas, os estudos em fonologia de L2 e de interlíngua têm discutido a relação entre transferência, desenvolvimento e universais linguísticos na aquisição de uma segunda língua. No entanto, novas visões sobre a aquisição da linguagem levaram os 
pesquisadores a rever posições sobre os conceitos de transferência, desenvolvimento e marcação. A Linguística Probabilística (BOD; HAY; JANEDY, 2003) lança um novo olhar para a aquisição do sistema sonoro da língua. Neste estudo, partimos de dois modelos que adotam noções probabilísticas: a Fonologia de Uso (BYBEE, 2001, 2006, 2010) e o Modelo de Exemplares (PIERREHUMBERT, 2003).

De acordo com Bod et al. (2003), a linguagem apresenta evidências de um sistema probabilístico. As categorias e a formação de palavras são gradientes e os efeitos de frequência estão em todos os contextos de análise, permeando as representações de processamento da língua e a mudança linguística. Todos os níveis de representação em fonética e fonologia mostram variação estatística e os falantes têm conhecimento implícito dessa mudança (PIERREHUMBERT, 2003). A codificação fonética de itens é probabilística, e esses itens competem entre si pela primazia. A Linguística Probabilística considera categorias linguísticas como distribuições e concebe o conhecimento linguístico não como uma quantidade limitada de restrições categóricas, mas como uma série de regras gradientes que pode ser caracterizada por distribuição estatística (BOD et al., 2003).

Para Bybee (2010), a linguagem não é uma atitude mental fixa. Se assim o fosse, as categorias seriam discretas. Como uma estrutura mental em uso constante e sempre filtrada por atividades de processamento que causam mudanças, a linguagem é variável e gradiente em suas formas. Em uma fonologia baseada no uso, a gramática é vista como a organização cognitiva da experiência que o falante tem com a linguagem (BYBEE, 2006). Com o uso, os itens linguísticos adquirem características pragmáticas, semânticas e fonológicas. Neste modelo, três pontos são fundamentais: o papel criativo da repetição, os efeitos da frequência e o caráter emergente da gramática. Seguindo a mesma linha de pensamento, no Modelo de Exemplares há também três bases fundamentais: detalhes fonéticos, gradiência das representações mentais, e a noção de frequência. Como resultado do contato com a língua, o falante produz um mapa de exemplares, formando nuvens que levam em conta fatores sociais, pragmáticos, semânticos, morfológicos, fonológicos e fonéticos. De acordo com Pierrehumbert (2001), uma nuvem de memória detalhada está associada a cada categoria, e as categorias mais frequentes têm mais exemplares e são mais facilmente ativadas do que as categorias menos frequentes. Dessa forma, a Linguística Probabilística é baseada em três pilares: o caráter dinâmico da linguagem, a gradiência das formas linguísticas e os efeitos da 
frequência. Alinhada à visão de dinamicidade, de gradiência e de frequência, está também a perspectiva do Inglês como Língua Franca, que parece ser uma combinação perfeita para os pressupostos dos modelos descritos acima.

\section{A PERSPECTIVA DO ENSINO/APRENDIZADO DE INGLÊS COMO LÍNGUA FRANCA}

Anos atrás, quando confrontados com a responsabilidade de escolher uma variedade de inglês para ensinar, os professores se viam diante de uma simples dicotomia: inglês americano ou inglês britânico? Hoje, a existência de "novos ingleses" (CRYSTAL, 2010) ganha terreno nas discussões sobre o status da língua inglesa na comunicação internacional. De acordo com Jenkins (2000), os falantes de inglês como língua materna perderam o direito de ditar os padrões de pronúncia para seu uso como L2. A partir de sua pesquisa, Jenkins (2000) estabelece uma série de itens com prioridade para o ensino de pronúncia de inglês, que ela chama LFC - Lingua Franca Core. Contendo características do inglês americano, do inglês britânico e de variedades do inglês como L2, o LFC, segundo Jenkins, permite uma certa liberdade. Como o foco é a inteligibilidade, as características específicas de variedades nativas que são difíceis para o aluno não devem ser consideradas para o ensino se não forem relevantes para a comunicação internacional. De acordo com Walker (2010), o ensino de pronúncia pode ter duas orientações diferentes, uma focada na comunicação com falantes nativos - o ensino de inglês como língua estrangeira (English as a Foreign Language - EFL), e outra focada na inteligibilidade internacional - o ensino de inglês como língua franca (English as a Lingua Franca - ELF). O autor apresenta uma série de preocupações e benefícios na adoção de uma abordagem para o ensino de inglês como língua franca e, em seguida, sugere várias técnicas de ensino. Em suma, Jenkins (2000) define as prioridades para o ensino de pronúncia de inglês como uma língua internacional em seu LFC, e Walker (2010) emprega o núcleo de Jenkins na sala de aula, que envolve não só a produção, mas também a percepção do sistema sonoro da língua inglesa. Conforme essa nova perspectiva, os professores e escritores de material didático devem requerer informações sobre os "novos ingleses" e o inglês brasileiro definitivamente será um deles. 


\section{ESTUDOS SOBRE O INGLÊS BRASILEIRO}

Aqui serão descritas duas áreas de estudo sobre o inglês brasileiro, uma considerando a pronúncia de palavras com o morfema - ed e outra considerando a colocação do acento de palavra.

\section{O morfema -ed}

Vários pesquisadores analisaram a produção de palavras terminadas com o morfema $e d$, e todos eles confirmam a tendência dos brasileiros de inserir uma vogal epentética na realização dessas palavras. Alves (2004) investigou a influência da instrução e mostrou que é possível ajudar os alunos a perceber detalhes do input. Delatorre (2006) examinou o ambiente fonológico precedente e descobriu que uma consoante precedente induz mais epêntese do que uma vogal e que algumas consoantes induzem a epêntese mais do que outras. Outra variável investigada por Delatorre (2006) foi a ortografia, que também pareceu exercer influência na produção de epêntese. Frese (2006) investigou a relação entre a produção e a percepção e sugeriu que esta última precede a primeira. Gomes (2009), depois de investigar a influência do ambiente fonológico anterior e cruzar categorias com frequência de palavras, concluiu que não apenas a frequência de ocorrência de item, mas também a frequência de tipo afeta a produção de palavras com o morfema - ed pelos brasileiros.

Para verificar a inteligibilidade de palavras que terminam em -ed por falantes brasileiros de inglês, Fernandes (2010) realizou uma pesquisa com ouvintes portugueses e indianos. Os brasileiros foram gravados inventando histórias e lendo pequenos textos. Os portugueses e os indianos ouviram a gravação e avaliaram o desempenho desses falantes. Segundo a pesquisadora, o nível de inteligibilidade variou entre os ouvintes portugueses, falantes de inglês como língua estrangeira (EFL), e os ouvintes indianos, falantes de inglês como segunda língua (ESL) ${ }^{3}$. Enquanto para os ouvintes portugueses os brasileiros tinham um nível de inteligibilidade de 74,19 \%, para os ouvintes da Índia o nível de inteligibilidade foi de $48,38 \%$. A autora sugere que as características de diferentes línguas maternas que causam

\footnotetext{
${ }^{3}$ Tradicionalmente, considera-se a diferença entre ESL - English as a Second Language - e EFL - English as a Foreign Language - em relação à perspectiva de ensino da língua. O ensino de ESL acontece em países onde a língua inglesa é dominante, enquanto que o de EFL acontece em países onde o inglês não é a língua dominante. Tendo outra perspectiva em foco, Walker (2010) considera EFL a forma de comunicação entre um falante nativo com um não nativo. Isso para contrapor o termo com ELF (English as a Lingua Franca), quando a comunicação se dá entre falantes não nativos de inglês.
} 
problemas para a comunicação devem ser apresentadas aos alunos por meio de instrução explícita. Por outro lado, as características que não causam problemas de comunicação não precisam ser consideradas.

\section{Acento de palavra}

Segundo Roach (2009), a colocação incorreta do acento pode causar problemas de inteligibilidade a falantes estrangeiros. Da mesma forma, Kenworthy (1987) sugere que, quando um falante não entende uma palavra, é muito comum o problema estar na colocação de acento ao invés da pronúncia inadequada de um som específico.

Cruz (2011) conduziu uma série de estudos que testa a inteligibilidade de brasileiros para falantes nativos de inglês. A autora sugere que o acento da palavra é o aspecto mais importante para a inteligibilidade de inglês como língua estrangeira. Vários estudos têm investigado as dificuldades de falantes brasileiros de inglês no acento de palavra. Dois deles (BRAWERMAN, 2006; BRAWERMAN-ALBINI, 2012) investigam um padrão de acento difícil para os brasileiros: palavras pré-proparoxítonas. Esse padrão de acento é praticamente inexistente no português brasileiro e pode-se considerar que os falantes brasileiros armazenam poucos exemplos desse padrão acentual, que é raro e improdutivo para eles.

Brawerman (2006) afirma que o padrão métrico desconhecido em palavras tais como re'frigerator, 'organizer, and 'fascinating é problemático mesmo para os falantes avançados de inglês. É provável que a fonte de erro seja a influência do padrão métrico da língua materna, combinado com input incorreto e falta de feedback negativo. Brawerman-Albini (2012) mostra que, apesar da dificuldade dos brasileiros em produzir esse padrão de acento, eles não parecem ter problemas de percepção. Esse estudo também explora o uso de treinamento perceptual e mostra ótimos resultados na produção final dos participantes, apesar do fato de terem sido expostos apenas ao input auditivo e não ter havido prática de produção.

Os resultados sugerem que o treinamento perceptual, que é normalmente usado com segmentos, pode também ter bons resultados para o acento. Esse estudo sugere que a exposição e a quantidade suficiente de input foram a chave para a formação da categoria de palavras pré-proparoxítonas, ilustrando a relevância da frequência. 


\section{INTELIGIBILIDADE}

Embora Jenkins (2000) não seja específica sobre a pronúncia de palavras que terminam com o morfema - $e d$, ela inclui encontros consonantais na lista de itens que podem causar problemas de comunicação e, portanto, devem receber prioridade pedagógica. A autora afirma que "como as L1s diferem amplamente em suas estruturas silábicas permitidas e, portanto, nas formas como os falantes fazem a simplificação de encontros consonantais, a inteligibilidade do inglês como língua internacional pode ser prejudicada" (JENKINS, 2000) ${ }^{4}$. A maioria dos falantes não-nativos tende a "simplificar encontros consonantais utilizando estratégia de adição em vez de eliminação, por causa do efeito de recuperação das palavras pelo ouvinte" (OP.CIT) ${ }^{5}$. Portanto, a epêntese e a paragoge podem ser estratégias comuns utilizadas por falantes de inglês como segunda língua. Palavras com o morfema -ed apresentam vários encontros consonantais que não são admitidos na estrutura silábica do português, o que leva falantes brasileiros a desenvolver estratégias de epêntese.

Quanto ao acento tônico, Walker (2010) afirma que a importância da colocação correta do acento para a inteligibilidade depende da perspectiva de uso do inglês, ou seja, como uma língua estrangeira ou como uma língua franca. No primeiro caso, o objetivo é a comunicação com falantes nativos e o acento da palavra tem um papel fundamental para a inteligibilidade. No segundo caso, no entanto, o objetivo é ser entendido por falantes nativos e não-nativos, tendo como meta a inteligibilidade e não a fala perfeita do nativo, e o acento da palavra não é tão relevante. Jenkins (2000) considera o acento da palavra "algo como uma zona cinzenta. $\mathrm{O}$ acento da palavra parece ser razoavelmente importante para o interlocutor nativo, mas raramente causa problemas de inteligibilidade nos dados da interlíngua e, quando isso acontece, sempre ocorre em combinação com outro erro fonológico" (OP. CIT) ${ }^{6}$. Assim, de acordo com ambos os autores, a importância do acento da palavra depende de como o inglês é tratado. No entanto, mesmo quando o inglês serve como uma língua franca, a

\footnotetext{
4 "because L1s differ widely in their permissible syllable structures and, thus, in their speakers' routes to cluster simplification, international English intelligibility is likely to be jeopardized". Todas as traduções neste artigo foram elaboradas pelas autoras.

5 "to simplify clusters using a strategy of addition instead of deletion, because of the effect of recoverability of their words for the listener"

6 "something as a grey area. Word stress seems to be reasonably important to L1 receivers, but rarely causes intelligibility problems in the Interlanguage Talk data and, where it does so, always occurs in combination with another phonological error"
} 
colocação do acento na palavra continua a ser importante devido ao acento nuclear, um dos elementos incluídos no LFC.

Como tanto a pronúncia de palavras com o morfema - ed como a colocação de acento na palavra são fatores muito característicos de sotaque de brasileiros ao falar inglês, é importante investigar o quanto esses fatores interferem na inteligibilidade. Para isso, foram realizados os dois estudos descritos nas próximas seções.

\section{ESTUDO 1 - INTELIGIBILIDADE DE PALAVRAS QUE TERMINAM COMO MORFEMA $-E D$}

Neste estudo, uma série de 10 frases a serem transcritas ortograficamente foi apresentada a 30 participantes. Os participantes foram divididos em três grupos de ouvintes: (1) falantes nativos de inglês, (2) falantes brasileiros de inglês, e (3) falantes não-nativos de inglês e não brasileiros.

\section{Os falantes}

As gravações, tiradas de Gomes (2009), eram compostas de duas falantes nativas de inglês (uma americana e uma britânica) ${ }^{7}$ e oito mulheres brasileiras em cinco diferentes níveis de proficiência de acordo com o Quadro Europeu Comum de Referência (A1, A2, B1, B2 e C1 $)^{8}$. As idades de todas as falantes variavam de 18 a 28 anos.

\section{As tarefas}

Os 30 participantes ouviam 10 sentenças tocadas duas vezes e tinham que transcrever cada sentença ortograficamente (Quadro 1). As sentenças foram tocadas duas vezes para garantir que os participantes se lembrassem da sentença completa durante a transcrição. Eles ouviam uma vez e transcreviam e, na sequência, ouviam uma segunda vez. Oito sentenças estavam no passado regular e tinham um ou dois verbos (10 verbos no total) e duas sentenças funcionaram como distratores. Todos os verbos das sentenças produzidas pelas brasileiras

\footnotetext{
${ }^{7}$ A americana, na época da coleta de dados, morava no Brasil há aproximadamente 10 anos. A britânica estava no Brasil há três meses.

${ }^{8}$ O Quadro Europeu Comum de Referência (QECR), elaborado pelo Conselho da Europa, fornece uma base comum para orientação no currículo de programas de ensino de línguas, na programação de conteúdo para exames, para elaboração de manuais, entre outros. O quadro descreve seis níveis de proficiência: utilizador em iniciação - A1, utilizador elementar - A2, utilizador independente limiar - B1, utilizador independente vantagem - B2, utilizador proficiente com autonomia - C1, e utilizador proficiente com maestria - C2 (GOMES, 2009).
} 
continham uma vogal epentética no morfema -ed, uma característica típica do jeito brasileiro de falar inglês. As sentenças do Estudo 1 são apresentadas no Quadro 1.

Quadro 1

Sentenças do Estudo 1

\begin{tabular}{|c|l|}
\hline FALANTE & SENTENÇA \\
\hline FA* & This seemed like the right thing to do. \\
\hline FB** & So I called out from my car. \\
\hline C2 & That was the luckiest trip of my life. \\
\hline C1 & We've changed the tire. \\
\hline B2 & She begged her husband to do the same. \\
\hline B2 & Bad figures made me even more tired. \\
\hline B1 & She loved him and was concerned about his health. \\
\hline A2 & She called me to ask if I wanted to help her. \\
\hline A1 & Suddenly somebody touched her arm. \\
\hline A1 & Actually she was in love with her. \\
\hline
\end{tabular}

* FA - falante americana **FB - falante britânica

\section{Os participantes}

Os participantes formavam três grupos diferentes de ouvintes.

\section{Falantes nativos de inglês (FN)}

Os 10 falantes nativos de inglês eram estudantes de Português para falantes de outras línguas - PFOL - em uma universidade federal em Curitiba, sendo nove norte-americanos e um belga que declarou ser falante nativo de inglês. Oito participantes se declararam familiarizados com brasileiros falando inglês e dois deles declararam que não estavam familiarizados.

\section{Falantes brasileiros $(F B)$}

O grupo de brasileiros era formado por 10 estudantes de Letras de uma universidade federal em Curitiba. Estavam todos no nível intermediário de inglês e tinham tido cerca de 400 horas de aula na universidade. A idade variava entre 21 e 25 anos e eram todos falantes nativos de português brasileiro.

\section{Falantes não nativos, diferentes de brasileiros (FNN)}

O terceiro grupo era composto por 10 participantes, sendo: um coreano, um dinamarquês, um norueguês, um holandês, um colombiano, um chileno e três franceses, que 
eram todos estudantes de PFOL em duas universidades federais em Curitiba e um falante de espanhol de origem haitiana. Eram todos proficientes em inglês. Cinco deles eram familiarizados com brasileiros que falam inglês e os outros cinco não eram.

\section{Resultados}

Os resultados do Estudo 1 são apresentados na Tabela 1. Como pode ser visto, os verbos mais inteligíveis para os falantes nativos foram tired, loved e called, todos produzidos por brasileiros em níveis B2, B1 e A2, respectivamente. As palavras foram transcritas corretamente por todos os ouvintes nativos. O grupo de brasileiros não obteve $100 \%$ de transcrições corretas em nenhum dos verbos, mas teve $90 \%$ em changed, begged, tired, loved, called and touched, pronunciados por falantes em todos os níveis, de A1 a C1. Para os falantes não-nativos o único verbo que teve $100 \%$ de transcrições corretas foi changed, produzido por uma falante brasileira de nível $\mathrm{C} 1$. Os verbos loved e called foram corretamente transcritos por $90 \%$ dos ouvintes não-nativos. Os verbos que foram os melhores transcritos, considerando os três grupos, foram loved e called, ambos pronunciados pelas brasileiras de níveis B1 e A2, respectivamente

Tabela 1

Transcrições dos Verbos com o Morfema-ed pelos Três Grupos de Participantes

Verbos transcritos
corretamente

Verbos transcritos

Verbos

Em branco corretamente, transcritos incorretamente

\begin{tabular}{|c|c|c|c|c|c|c|c|c|c|c|c|c|}
\hline \multirow{2}{*}{ SPEAKER } & \multicolumn{9}{|c|}{ mas sem -ed } & \multirow[b]{2}{*}{ FN } & \multirow[b]{2}{*}{ FB } & \multirow[b]{2}{*}{ FNN } \\
\hline & FN & FB & FNN & $\mathbf{F N}$ & FB & FNN & $\mathbf{F N}$ & FB & FNN & & & \\
\hline SEEMED -FA* & $70 \%$ & $20 \%$ & $10 \%$ & $30 \%$ & $80 \%$ & $60 \%$ & 0 & 0 & 0 & 0 & 0 & $30 \%$ \\
\hline CALLED -FB** & $30 \%$ & $30 \%$ & $40 \%$ & 0 & 0 & 0 & $30 \%$ & $10 \%$ & $10 \%$ & $40 \%$ & $60 \%$ & $50 \%$ \\
\hline CHANGED - C1 & $80 \%$ & $90 \%$ & $100 \%$ & $20 \%$ & $10 \%$ & 0 & 0 & 0 & 0 & 0 & 0 & 0 \\
\hline BEGGED - B2 & $80 \%$ & $90 \%$ & $60 \%$ & $10 \%$ & 0 & 0 & 0 & 0 & 0 & $10 \%$ & 0 & $40 \%$ \\
\hline TIRED - B2 & $100 \%$ & $690 \%$ & $80 \%$ & 0 & 0 & 0 & 0 & $10 \%$ & 0 & 0 & 0 & $20 \%$ \\
\hline LOVED - B1 & $100 \%$ & $690 \%$ & $90 \%$ & 0 & $10 \%$ & $10 \%$ & 0 & 0 & 0 & 0 & 0 & 0 \\
\hline CONCERNED - B1 & $30 \%$ & $50 \%$ & $30 \%$ & 0 & 0 & 0 & $40 \%$ & $10 \%$ & 0 & $30 \%$ & $40 \%$ & $70 \%$ \\
\hline CALLED - A2 & $100 \%$ & $690 \%$ & $90 \%$ & 0 & $10 \%$ & 0 & 0 & 0 & $10 \%$ & 0 & 0 & 0 \\
\hline WANTED - A2 & $50 \%$ & $70 \%$ & $40 \%$ & $40 \%$ & $30 \%$ & $50 \%$ & $10 \%$ & 0 & 0 & 0 & 0 & $10 \%$ \\
\hline TOUCHED - A1 & $70 \%$ & $90 \%$ & $40 \%$ & 0 & 0 & 0 & $20 \%$ & $10 \%$ & $40 \%$ & $10 \%$ & 0 & $20 \%$ \\
\hline
\end{tabular}


Os desempenhos mais fracos apresentados pelos três grupos (Tabela 1) são para o verbo called produzido pela falante nativa britânica (FB) e o verbo concerned produzido por uma falante de nível B1 brasileira. Outro verbo que teve um número mais baixo de acertos pelos três grupos foi wanted - 50\% dos participantes nativos, $70 \%$ dos participantes brasileiros e $40 \%$ dos participantes não-nativos. Os verbos called (pela FB) e concerned, quando não corretamente transcritos, foram trocados por outra palavra (concerned por closer, confident [três vezes] por quality, e called por crawled [duas vezes]), enquanto que o verbo wanted foi na maior parte transcrito sem o morfema $-e d$. O verbo touched foi também trocado por outras palavras por participantes dos três grupos de ouvintes (por tortured [5 vezes], told e tore). $\mathrm{O}$ verbo produzido pela falante americana (seemed) foi transcrito sem o morfema -ed por $57 \%$ dos participantes. Até $30 \%$ do grupo de ouvintes nativos transcreveram esse verbo no presente.

\section{DISCUSSÃO}

Alguns resultados interessantes nessa tarefa podem ser destacados. Comecemos com a primeira sentença, produzida pela falante americana, conforme espectrogramas e oscilogramas nas Figuras 1 e 2.

Figura 1

This seemed like the right thing to do.

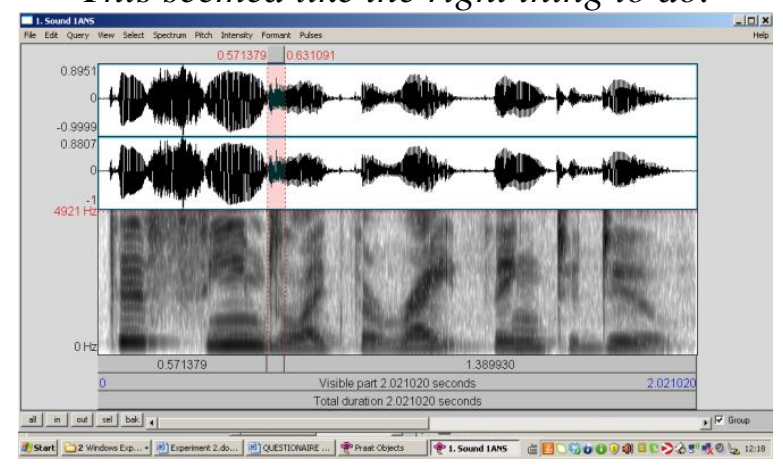

Embora esteja claro no espectrograma que a alveolar plosiva [d] foi produzida pela falante, ela não foi percebida por $30 \%$ dos nativos, $80 \%$ dos brasileiros e $60 \%$ dos ouvintes não-nativos. Isso significa que o morfema, principalmente nos alomorfes [t] e [d], não é saliente. Essa pode ser uma das razões pelas quais os brasileiros tendem a pronunciar o "e" do morfema. Jenkins (2000) é enfática quando afirma que, na produção de encontro consonantal, 
acrescentar um elemento é preferível a um apagamento. Tendo isso em mente, poderíamos concordar com Jenkins (2000) quando diz que não-nativos fluentes em inglês são melhor compreendidos em um contexto internacional do que falantes nativos.

Figura 2

She called me to ask if I wanted to help her.

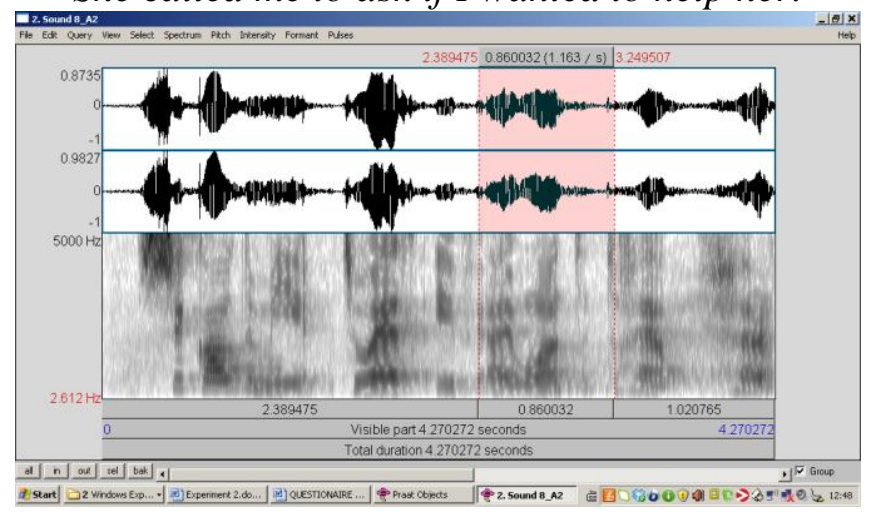

Embora não saliente, a falante produziu um segundo [t] antes da preposição to, como mostra o espectrograma. A falta da vogal epentética, que nesse caso deve ser pronunciada, levou uma boa parte dos ouvintes a escrever a palavra sem o - ed, $40 \%$ dos nativos, 30\% dos brasileiros e $50 \%$ dos ouvintes não-nativos. É interessante notar que o melhor resultado nesse verbo foi obtido pelos brasileiros.

Como mencionado acima, os melhores resultados da transcrição ocorreram com os verbos called e loved, pronunciados pelas brasileiras de nível B1 e A2, respectivamente. Mesmo com um baixo nível de proficiência, houve um bom nível de inteligibilidade. Podemos inferir que a vogal epentética não causa muitos problemas de inteligibilidade, pois o resultado geral foi de 76,2 \% de transcrição correta e 8,7\% de transcrição do verbo correto sem o morfema pelos ouvintes nativos, $82,5 \%$ e 7,5\%, respectivamente, pelos brasileiros, e $66,2 \%$ e 7,5\%, pelos ouvintes não-nativos. É importante lembrar que $20 \%$ dos ouvintes nativos e $50 \%$ dos ouvintes não-nativos disseram que não estavam familiarizados com brasileiros falando inglês. De acordo com o Modelo de Exemplares, a experiência determina a percepção, categorização e armazenamento (BYBEE, 2001). Bybee cita Johnson (1997), que: ouvintes não só identificam corretamente as palavras ou enunciados produzidos por diferentes falantes (cujas propriedades acústicas variam consideravelmente), mas também identificam corretamente a voz de diferentes falantes que ouviram antes. Em um Modelo de Exemplares, 
todas os itens percebidos são classificados e armazenados, e categorias são criadas para representar diretamente a variação encontrada (BYBEE, 2001, p.51) ${ }^{9}$.

Também vale a pena comentar sobre os verbos que tiveram os números de acertos mais baixos: concerned e touched. Podemos inferir que a razão poderia ser a menor frequência lexical dos dois verbos, quando comparados com loved e called, os verbos com melhores resultados. No entanto, existem dois aspectos envolvidos nas transcrições desses verbos que merecem alguma discussão, dois aspectos que não estão relacionados com a produção do morfema - ed, mas sim com o LFC de Jenkins. O verbo concerned foi pronunciado com um erro na sílaba tônica: ['konserned]. Esse fato resultou em má compreensão por $40 \%$ dos ouvintes nativos, que o transcreveram closer (um ouvinte) e confident (três ouvintes), enquanto um dos brasileiros o transcreveu como quality. No caso dos ouvintes não-nativos, 70\% deixaram um espaço em branco para o verbo concerned. De acordo com Jenkins (2000), o acento tônico da palavra é importante para ouvintes que têm o inglês como L1, mas não é fundamental para a inteligibilidade de palavras individuais em inglês como língua internacional, "pois as regras são tão complexas que são difíceis de ser ensinadas" (p.150) ${ }^{10}$. Está claro em nossos dados que, para alguns dos ouvintes nativos o acento na sílaba errada causou uma falha de comunicação, mas para os não-nativos não é possível afirmar se foi realmente o acento que causou o problema de inteligibilidade nessa palavra.

Quanto ao verbo touched, outro item do LFC de Jenkins poderia ser a razão para a falta de inteligibilidade: o som da vogal. Os brasileiros desta pesquisa tendem a pronunciar a palavra touch como [totS] ou [toutS]. É evidente que a mudança na vogal causou o problema de inteligibilidade, pois dois dos ouvintes nativos e três dos não-nativos transcreveram o verbo como tortured. Duas outras transcrições incorretas foram tore (por um não-nativo) e told (por um brasileiro). Os outros $90 \%$ dos brasileiros, por outro lado, fizeram transcrição correta, uma vez que esse verbo, pronunciado dessa forma, é comum para eles.

\footnotetext{
${ }^{9}$ argues for an exemplar model of speech perception to account for the fact that hearers not only correctly identify words or utterances produced by different speakers (whose acoustic properties vary considerably), but also correctly identify the voice of different speakers they have heard before. In an exemplar model all perceived tokens are categorized and stored, creating categories that directly represent the variation encountered.

10 "as the rules are so complex as to be unteachable"
} 
Esse fato pode reforçar a afirmação de Jenkins de que qualidades regionais de vogais de L2 podem ser permitidas, desde que sejam consistentes.

\section{ESTUDO 2 - ACENTO DE PALAVRA}

Este estudo apresenta resultados de uma tarefa semelhante ao Estudo 1. No entanto, o seu foco foi o acento de palavra. Os participantes também foram divididos em três grupos de ouvintes: (1) falantes nativos de inglês, (2) falantes brasileiros de inglês, e (3) falantes nãonativos de inglês, não brasileiros.

\section{Os falantes}

Oito sentenças foram gravadas por falantes brasileiros de inglês, cujo nível foi considerado B1 (cerca de 400 horas de instrução em inglês no curso de graduação em Letras). Duas sentenças foram gravadas por uma falante nativa americana para servir como um controle para o experimento.

A tarefa

A exemplo do Estudo 1, os participantes ouviram as 10 sentenças (Quadro 2) tocadas duas vezes e tiveram que transcrever cada sentença ortograficamente. Todas as sentenças continham uma palavra sufixada com acento na quarta sílaba de traz para frente, ou seja, uma pré-proparoxítona. Os falantes brasileiros tinham colocado o acento em uma das três últimas sílabas e o falante americano tinha colocado o acento corretamente nas duas palavras.

Quadro 2

Sentenças do Estudo 2

\begin{tabular}{|l|l|}
\hline FALANTE & SENTENÇA \\
\hline FA & I would categorize this as a work of art. \\
\hline FB1 & I have a calculator in my pocket. \\
\hline FB2 & It's a really satisfying job. \\
\hline FB3 & The architecture of the town is very modern. \\
\hline FB4 & A modifier gives extra information about a word. \\
\hline FB5 & There is only one elevator in my building. \\
\hline FB6 & The mind has great generative capacity. \\
\hline FB7 & He was arrested and subsequently freed. \\
\hline FB8 & Bright colors characterize his paintings. \\
\hline FA & Food is marginally more expensive. \\
\hline
\end{tabular}




\section{Os participantes}

Os participantes formaram três grupos.

\section{Falantes nativos (FN)}

O grupo de falantes nativos foi composto por sete participantes: seis norte-americanos e um belga que declarou que sua língua materna era o Inglês. Os participantes estavam vivendo no Brasil quando o teste foi realizado.

\section{Falantes brasileiros $(F B)$}

O grupo de falantes brasileiros foi composto por 12 alunos que tinham ao menos nível intermediário da língua e estavam cursando uma disciplina de fonologia do inglês. Os dados foram coletados durante as aulas com todos os alunos juntos. Todos os participantes disseram que sua língua nativa era o português e suas idades variavam de 21 a 29 anos.

\section{Falantes não nativos, diferentes de brasileiros (FNN)}

O grupo de falantes não-nativos de inglês foi composto por sete participantes: três franceses, um dinamarquês, um coreano, um holandês e um haitiano. A maioria deles vivia no Brasil há algum tempo antes do teste e faziam um curso de português para falantes de outras línguas. O haitiano, no entanto, não morava no Brasil.

\section{Resultados}

Os resultados do Estudo 2 são apresentados na Tabela 2. Pode-se observar que os falantes nativos foram melhores na transcrição das sentenças gravadas, seguidos pelos nãonativos e, em seguida, pelos brasileiros. Também podemos ver que os brasileiros foram os que mais tiveram problemas com a primeira e última sentenças, aquelas produzidas por uma falante americana. 
Tabela 2

Resultados do Estudo 2

\begin{tabular}{llllc}
\hline \multicolumn{4}{c}{ WORD } & \multicolumn{4}{c}{ Palavras transcritas } \\
corretamente \\
\hline
\end{tabular}

FN: falantes nativas; FB: falantes brasileiros; FNN: falantes não-nativos

Considerando-se especificamente a inteligibilidade de palavras individuais, as palavras mais inteligíveis para os falantes nativos foram categorize (produzida por outro falante nativo), calculator, elevator e characterize. Para os brasileiros, a única palavra que foi $100 \%$ inteligível foi calculator e para o grupo $\mathrm{FNN}$ as palavras totalmente inteligíveis foram calculator, elevator e characterize. Além disso, observando-se as porcentagens de acerto de cada palavra, pode-se notar que essas foram as mais inteligíveis para os participantes em geral. Quanto às palavras com os resultados mais baixos, a menos inteligível para o grupo FN foi architecture, com apenas $29 \%$ de acertos nas transcrições. Para o grupo FB, foi a palavra satisfying e para o grupo FNN, cinco palavras tiveram $43 \%$ de transcrições corretas: satisfying, architecture e modifier e as duas palavras produzidas pelo falante nativo (categorize e marginally). Em geral, as palavras menos inteligíveis foram satisfying, marginally, modifier e architecture. Uma possível explicação para o contraste entre as palavras mais e menos inteligíveis é a frequência das palavras, pois os falantes podem ter tido mais exposição às palavras que eles foram capazes de transcrever corretamente. Além disso, a frequência de tipo pode ter desempenhado um papel importante, já que as palavras mais inteligíveis tinham o sufixo -ate e -ize. A única exceção foi com a palavra categorize, mas que foi pronunciada pela falante nativa. 


\section{DISCUSSÃO}

Como mostrado na Tabela 2, neste estudo os falantes brasileiros foram mais inteligíveis para os falantes nativos, seguidos pelos falantes não-nativos. Analisando apenas as palavras produzidas pela falante nativa, o resultado é o mesmo: mais uma vez, o grupo com a maior taxa de inteligibilidade foi o de falantes nativos e o menor foi o de brasileiros. $\mathrm{O}$ fato de que os brasileiros também tiveram os maiores problemas em entender os falantes nativos pode implicar que este grupo de participantes pode ter tido dificuldades em geral, e não só com o acento tônico (apesar de ser um grupo de futuros professores de inglês cursando uma disciplina de Fonologia).

As palavras que não eram inteligíveis foram muitas vezes trocadas por outras palavras. Alguns participantes do grupo FN trocaram a palavra satisfying por expressões como set finelsits fine; architecture por texture, catcher por caricature, e modifier por frases como I'm going to fire / I want to fire. O grupo FB teve mais problemas com satisfying, substituída por find e duas vezes por fine, e marginally, substituída uma vez por largely e outra pelo nome Marjorie. O grupo FNN teve alguns problemas com as palavras satisfying e architecture, que em alguns casos foram alteradas para fine/six times e structureltexture, respectivamente.

De acordo com Jenkins (2000), o acento da palavra não afeta a inteligibilidade de falantes não-nativos. Os dados desta pesquisa são limitados, no entanto, algumas respostas parecem indicar que uma palavra com o acento na sílaba indevida pode realmente levar a uma falta de inteligibilidade, uma vez que o ouvinte pode tentar adaptar a frase inteira para que ela faça sentido com a palavra que ele compreendeu. A sentença It's a really satisfying job, por exemplo, foi transcrita por um ouvinte como It finally found a fine job. A sentença The architecture of the town is very modern foi transcrita por um participante do grupo FNN como The structure of the tone is very modern.

O mesmo aconteceu quando os falantes nativos foram os ouvintes. Esses dados corroboram a afirmação de Kenworthy (1987) de que a colocação incorreta do acento pode afetar a inteligibilidade para falantes nativos. A sentença The architecture of the town is very modern foi transcrita por um ouvinte do grupo $\mathrm{FN}$ como The texture of their tongue is very modern. O participante ainda colocou alguns pontos de interrogação no final da frase, mostrando que o significado da frase para ele era estranho. Ao mudar a palavra architecture para texture, ele também mudou town para tongue, tornando a palavra modern sem sentido. 
Outro exemplo ocorreu na sentença A modifier gives extra information about a word. Um participante a transcreveu como I want to fire and give extra information about a word.

\section{CONSIDERAÇÕES FINAIS}

O morfema - ed não é saliente mesmo quando produzido e percebido por falantes nativos. Parece que o contexto do tempo passado é importante para a inteligibilidade. A proposição de Jenkins (2000) de que a adição é melhor do que a eliminação nos encontros consonantais pode ser uma explicação interessante para a inteligibilidade da produção de epêntese por brasileiros no passado de verbos regulares.

Tanto a frequência de item quanto a frequência de tipo devem desempenhar um papel importante na inteligibilidade, não só relacionadas a contextos fonéticos e morfológicos, mas também a fatores sociais e pragmáticos. Palavras de maior frequência são mais inteligíveis, mesmo quando produzidas com uma vogal epentética. Quanto ao acento tônico, as palavras mais problemáticas para os brasileiros foram aquelas de menor frequência (por exemplo, marginally e modifier) e as palavras pronunciadas pelo falante nativo, que pode mostrar a influência da frequência de tipo. Um padrão de acento não familiar para os brasileiros afetaria sua compreensão.

Segundo este estudo, a colocação incorreta de acento pelos brasileiros pode levar a problemas de inteligibilidade, na seguinte ordem: brasileiros > falantes não-nativos $>$ falantes nativos. Este resultado parece contradizer a afirmação de Jenkins de que o acento da palavra não causa problemas de inteligibilidade para falantes não-nativos. No entanto, os dados deste estudo são limitados e devem ser considerados com cuidado. Mais estudos sobre a inteligibilidade do acento de palavra para falantes nativos e não-nativos devem ser conduzidos para acrescentar mais informações aos resultados um tanto contraditórios deste estudo.

\section{REFERÊNCIAS}

ALVES, U. K. O papel da instrução explícita na aquisição fonológica de inglês como L2: evidências fornecidas pela teoria da otimidade. Dissertação de Mestrado Universidade Católica de Pelotas, 2004.

BOD, R.; HAY, J.; JANEDY, S. Probabilistic linguistics. Cambridge, MA: MIT Press, 2003. BRAWERMAN, A. Uma análise de erros de estudantes brasileiros de inglês na acentuação de palavras com sufixos. Dissertação de Mestrado. Universidade Federal do Paraná, 2006. 
BRAWERMAN-ALBINI, A. Os efeitos de um treinamento de percepção na aquisição do padrão acentual pré-proparoxítono da língua inglesa por estudantes brasileiros. Tese de Doutorado. Universidade Federal do Paraná, 2012.

BYBEE, J. Phonology and language in use. Cambridge, UK: Cambridge University Press, 2001.

BYBEE, J. From usage to grammar: the mind's response to repetition. Language. 82 (4), p.711-733, 2006.

BYBEE, J. Language, usage and cognition. Cambridge, UK: Cambridge University Press, 2010.

CRUZ, N. C. Inteligibilidade fonológica de aprendizes brasileiros de inglês. Anais Eletrônicos do IX Congresso Brasileiro de Linguística Aplicada. Rio de Janeiro, 2011.

CRYSTAL, D. English as a global language. 2.ed. Cambridge, UK: Cambridge University Press, 2010.

DELATORRE, F. Brazilians EFL learners' production of vowel epenthesis in words ending in - ed. Dissertação de Mestrado. Universidade Federal de Santa Catarina, 2006.

FERNANDES, R. K. M. A inteligibilidade de pronúncia das palavras terminadas em -ed por falantes de inglês não nativos. Língua portuguesa: ultrapassar fronteiras, juntar culturas. Universidade de Évora, Lisboa, 2010.

FRESE, R. A. The relation between perception and production of words ending in -ed by Brazilian EFL learners. Dissertação de Mestrado. Universidade Federal de Santa Catarina, 2006.

GOMES, M. L. C. A produção de palavras do inglês com o morfema -ed por falantes brasileiros: uma visão dinâmica. Tese de Doutorado. Universidade Federal do Paraná, 2009.

JENKINS, J. The Phonology of English as an international language. Oxford, UK: Oxford University Press, 2000.

KENWORTHY, J. Teaching English Pronunciation. Essex: Longman, 1987.

PIERREHUMBERT, J. B. Exemplar dynamics: Word frequency, lenition and contrast. In: BYBEE, J.; HOPPER, P. (Eds.). Frequency effects and the emergence of linguistic structure. Amsterdam: John Benjamins, 2001. p.137-157.

PIERREHUMBERT, J. B. Phonetic diversity, statistical learning, and Acquisition of phonology. Language and Speech. 46, (2-3), p.115-154, 2003.

ROACH, P. English Phonetics and Phonology: a practical course. Cambridge: Cambridge University Press, 2009.

WALKER, R. Teaching pronunciation of English as a Lingua Franca. Oxford: Oxford University Press, 2010. 